\title{
Perceptions of Mothers and Caregivers Regarding the Factors Affecting Low Uptake of Measles Immunisation Among Children Under 5 Years in Nyangana District, Namibia
}

\author{
Alice Lifalaza ${ }^{1}$, Ruth Stern $^{2} \&$ Daniel Opotamutale Ashipala ${ }^{1}$ \\ ${ }^{1}$ Department of Community Health Nursing Science, School of Nursing, Faculty of Health Sciences, University of \\ Namibia (UNAM), Rundu, Namibia \\ ${ }^{2}$ School of Public Health, Faculty of Community and Health Sciences, University of Western Cape (UWC), \\ Rundu, Namibia \\ Correspondence: Ms Alice Lifalaza department of Community Health Nursing Science School of Nursing, Faculty \\ of Health Sciences, University of Namibia (UNAM), PO Box 88, Kaisosi Road, Rundu, Namibia. Tel: \\ 264-066-268-6028. E-mail: alifalaza@unam.na
}

Received: August 17, 2018 Accepted: September 4, 2018 Online Published: September 7, 2018

doi:10.5539/gjhs.v10n10p74 URL: https://doi.org/10.5539/gjhs.v10n10p74

\begin{abstract}
Immunisation is considered to be amongst the most successful and cost-effective disease prevention interventions available. The aim of this study was, to investigate the perceptions of mothers/caregivers on the factors that impact on the uptake of measles immunisation in the Nyangana Health District, with a view to improving measles immunisation coverage.

A qualitative exploratory study design was used to collect data from the study participants by the use of interviews. Data was audio-taped and transcribed verbatim. The recorded interviews were translated from the Gciriku language to English. Data was analysed through the use of the Thematic Content Analysis approach. Mothers whose children were vaccinated and those whose children were not vaccinated had both positive perceptions about immunisation.

The findings indicates that, despite awareness and willingness for some mothers to bring their children for subsequent follow-up vaccinations, barriers such as inability to pay for transport, lack of support for single mothers and absence of support structures was hindering factors to immunisation uptake. Additionally, health system factors such as health care provider attitudes, staff shortages, inconvenient immunisation services, time constraints, inadequate outreach services and lack of tracking services for children who missed their measles immunisation were found to have an influence on the immunisation uptake.

The children who missed their immunisation doses were mostly for single mothers and for those mothers who stayed far away from the clinic. The study concludes that the relationship between health care providers and mothers/caregivers and support from other social structures, should be good, in order to motivate mothers to use immunisation services.

The study recommends that the following aspects be addressed, as they have the potential to improve the low uptake of measles immunisation: patient/provider relationship, information sharing, and supervision in the health facility, access to services, availability of outreach services, improved data tracking and active involvement of all stakeholders. These children should be targeted through improved outreach services and the use of health extension workers for contact tracing of children who missed their immunisation.
\end{abstract}

Keywords: low uptake of measles immunisation, children under 5 years, Namibia

\section{Introduction}

Immunisation is a proven mechanism for controlling and eliminating life-threatening infectious diseases such as measles. The World Health Organization stated that immunisation prevents an estimated 2 to 5 million deaths worldwide annually (WHO/UNICEF, 2013). Immunisation is stated to be the most effective public health intervention in the world for saving lives and for promoting good health. Immunisation is also an intervention that saves money (Hill, 2013). The Expanded Programme on Immunisation (EPI) Fact Sheet states that, "According to 
WHO every dollar spent on vaccine saves seven dollars in medical costs and 25 dollars in overall costs related to vaccine preventable diseases" (WCDoH, 2005). The EPI Programme was initiated by the World Health Organization (WHO) in 1974 to provide protection against six childhood diseases, namely polio, diphtheria, tuberculosis, pertussis (whooping cough), measles and tetanus (Greenwood, 2014).

The aim of the EPI is to reduce morbidity and mortality for vaccine-preventable childhood diseases. It was an initiative that aimed to build on the success of the WHO Smallpox Eradication Programme, and to assist national immunisation programmes in developing countries that faced challenges. According to the WHO guideline, a child is considered to be fully immunised if he or she received: one dose of Bacillus Calmette-Guerin vaccine (BCG) against Tuberculosis, three of DPT to prevent diphtheria, pertussis and tetanus, at least three doses of the polio vaccine and one dose of the measles vaccine which should be received during the first year of life (MoHSS, 2013). The success of any immunisation programme, such as childhood immunisation programmes, depends on meeting the herd immunity for the purpose of preventing local and endemic outbreaks and epidemics for its targeted diseases.

The Progress has been noted in 2010, the World Health Assembly (WHA) set three milestones for measles control by 2015: 1) increase routine coverage with first dose of measles-containing virus vaccine (MCV1) among children aged 1 year to $\geq 90 \%$ at the national level and,to $\geq 80 \%$ in every district; 2 ) reduce global annual measles incidence to $<5$ cases per million population and 3) reduce global mortality by $95 \%$ from the 2000 estimate (Dabbagh et.al:2017) However, despite improved interventions and a history of success, progress on full vaccination is reported to remain low and irregular in Sub-Saharan Africa, including in Namibia.

The EPI Programme on immunisation in Namibia was established to strengthen routine immunisation with a focus to achieve and maintain an immunisation coverage that is above $90 \%$ in each district MoHSS (Ministry of Health and Social Services, 2008). The National Immunisation Days (NID) review discovered constant challenges related to reaching children under the Reaching Every District Approach in both urban and very remote settings, indicating the need for more efforts in advocacy and social mobilization in order to reach unimmunised and under immunised children (WHO/UNICEF, 2013). The estimated coverage for Namibia was 82\% in 2013, 83\% in 2014 and $85 \%$ in 2015 , indicating the performance that is below the milestone of $\geq 90 \%$ at national level (Masresha et.al, 2017).

The findings of the Health Facility Survey have revealed that epidemics of measles have been reported in Namibia, mainly in regions bordering Angola. Kavango being one of these regions to (Ministry of Health and Social Services, 2010), measles outbreaks were also reported at the beginning and middle of 2014 respectively (UNICEF, 2014) The Kavango region coverage for DPT 3 was 86.9 compared to $55 \%$ of measles, indicating a drop-out rate of 31.9\% MoHSS (Ministry of Health and Social Services, 2008). The high drop-out rate between DPT 3 and measles raises questions about uptake, as it can be reasonably assumed that the low uptake of measles immunisation would precede epidemics of measles. It is thus assumed that the low performance on measles coverage might have contributed to ongoing outbreaks in the previous years in Namibia, including the year 2013. Kavango region was the most affected, with Nyangana district being one of the three affected districts in the Kavango region (Ministry of Health and Social Services, 2014).

The Nyangana district is the third largest of the four districts in the Kavango region (situated now in Kavango East in the new region demarcations), in the north-east of Namibia, and one of the regions bordering Angola. It is situated south of the Kavango river and covers a surface area of $15000 \mathrm{~km}^{2}$. It is a rural setting with more of a concentration on subsistence agricultural activities. It is predominantly occupied by the Gciriku people and other smaller ethnic groupings, e.g. Nyemba, San and Mbukushu. The region is densely populated along the Kavango River, with fewer people scattered in the inland. Fishing and commercial farming are some of the agricultural enterprises.

\section{Goals and Objectives}

The goal of the study was to investigate the perception of mothers/caregivers on factors that impact on the uptake of measles immunisation in the Nyangana Health District, with a view to improving measles immunisation coverage. The study objectives was to explore mothers' or caregivers' perceptions about barriers to the uptake of measles immunisation.

\section{Research Design and Methods}

\subsection{Design}

A cross-sectional qualitative and explorative design (Brink, van Rensburg, \& van der Walt, 2013). 


\subsection{Study Population}

The study population included all adult mothers/caregivers of children under five years for both children who received, and those who did not receive measles vaccination, in Nyangana District at the selected health facility.

\subsection{Inclusion and Exclusion Criteria}

All mothers of children under the age of 5 who access services at Karukuta Clinic at the time of the study who were willing to participate were included in the study. All mothers with children of 5 years and above and those with children age $0-8$ months were excluded from the study. In addition, mothers who were not willing to participate were also excluded in the study.

\subsection{Sampling and Sample Size}

In qualitative studies the size of a sample is guided by the purpose of the inquiry. Therefore in this study there was no specification of the sample size but data saturation was determined by the sample size. Data saturation was reached with ten (10) participants. Maree (2016), describe purposive sampling as a strategy that is used in qualitative studies whereby participants are grouped according to predetermined criteria that are relevant to a particular research question. Purposive sampling was used to select participants in this study.

\subsection{Data Collection Tool}

In this study, in-depth interviews were used as the primary source of data collection. This data collection method was used for the study, as it is considered to be a relevant tool to use when the researcher seeks to learn about people's feelings, thoughts and experiences (Maree (2016).

\subsection{Data Collection Methods}

The researcher conducted face to face in-depth interviews with the 10 mothers in the language of their choice. Prior to the data collection process, verification was done from the children's immunization cards shown to the researcher and research assistant, to ascertain whether measles immunization was received or not.

\subsection{Data Analysis}

Data was analysed through the use of the Thematic Content Analysis approach. The transcribed interviews and narratives from the research assistant's notes were organised into codes, sub-themes and main themes (Robson, 2011) and (Maree, 2016). Themes were integrated and interpreted, by identifying facilitating factors for those who took their children for immunisation, and barriers for those who did not take theirs.

\section{Ethical Considerations}

Ethical principles were adhered to by the researcher. The purpose of the study was explained to the participants. Written consent forms were obtained, prior to the interview, from those who were willing to participate in the study. The voluntary nature of participation was made clear prior to data collection, informing participants that they could withdraw if they so wished without any consequences, or penalty in future with regard to the use of services at the clinic. They were also reassured that their identities would not be revealed. To ensure this, codes were used in such a way that participants would remain anonymous. The researcher used number codes to identify mothers whose children had received measles immunization and symbol codes for mothers whose children did not receive measles immunization.

\section{Results}

\subsection{Socio Demographic Description of Study Participants}

Participants were mothers of different age groups between 24 and 37 years; there were no caregivers. Table 1 below presents the participants and their characteristics. It is evident from the table that the majority were unemployed. Although the majority of participants were married and lived together as husbands and wives, they indicated that in their community the main form of marriage was by custom recognition. This form of traditional marriage system is acceptable in their settlement. Among the married participants, only one participant (PA) had a marriage certificate from church. All mothers had two to six children; the majority had four children. The mothers were all Christians, Catholic being the dominant denomination. The education level of participants was between Grade 3 and Grade 11; only one participant (P2) had no schooling. 
Table 1. Characteristic of Participants

\begin{tabular}{ll}
\hline Age & Total \\
\hline $27-30$ & 5 \\
$31-40$ & 4 \\
$41-50$ & - \\
$51-60$ & 1 \\
Unknown & \\
\hline Marital Status & 4 \\
\hline Single & 6 \\
Married & - \\
Co-habitating & - \\
Widowed & \\
\hline Educational Level & 5 \\
\hline Grade 1-7 & 4 \\
Grade 8-12 & - \\
Tertiary Education & 1 \\
No education & \\
\hline Employment & 0 \\
\hline Employed & 10 \\
Unemployed &
\end{tabular}

Table 2. Classification of results

\begin{tabular}{|c|c|c|}
\hline THEMES & SUB-THEMES & CODES \\
\hline \multirow[t]{9}{*}{5.2 Individual factors } & $\begin{array}{l}\text { 5.2.1 Understanding of measles } \\
\text { immunisation }\end{array}$ & $\begin{array}{l}\text { Awareness of benefits of measles vaccine } \\
\text { Knowledge of effects of missing measles dose }\end{array}$ \\
\hline & 5.2.2 Education level & $\begin{array}{l}\text { Ability to read information on child Health } \\
\text { Passport }\end{array}$ \\
\hline & 5.2.3 Forgetfulness & Reminder for follow-up immunisation \\
\hline & 5.2.4 Travelling & Unplanned travelling \\
\hline & 5.2.5 Commitment & Competing priority activities \\
\hline & & Lack of self-motivation \\
\hline & & Laziness \\
\hline & & Ignorance \\
\hline & & Alcohol use \\
\hline \multirow[t]{4}{*}{ 5.3 Socio-cultural factors } & 5.3.1 Beliefs & Religious beliefs \\
\hline & & Traditional remedies \\
\hline & 5.3.2 Support structures & Family support \\
\hline & & Social support \\
\hline 5.4 Socio-economic factors & 5.4.1 Unemployment & Effects of poverty to cater for repeated visits \\
\hline \multirow[t]{3}{*}{ 5.5 Health System factors } & 5.5.1 Long distance & Transport cost \\
\hline & & Long distance walking \\
\hline & 5.5.2 Availability of services and vaccines & Access to services \\
\hline
\end{tabular}


Unavailability of out-reach services

5.5.3 Staff shortage at clinic Long waiting time for service

Lack of order

5.5.4 Attitudes of staff Interaction

\subsection{Individual Factors}

\subsubsection{Understanding the Importance of Measles Immunisation}

The understanding that measles caused fever, affected the eyes and that it was a severe illness leading to blindness, disability and death was considered important. The perceived knowledge and understanding of the severity of measles as a disease and its complications contributed to the understanding that influenced mothers to take or not to take their children for immunisation.

"I was informed by my elders that the disease [measles] can affect the eyes and cause blindness if a child is not immunised." (P5)

The understanding of the severity of measles as a disease, and the benefits and importance of measles immunisation to prevent this was one of the facilitating factors for mothers to take their children for measles immunisation.

“... it [measles] affects the eyes, rashes all over the body and fever ... we were informed by the nurse to take our children for immunisation ... to prevent children from getting the disease ... if a child did not get measles immunisation is at danger of getting it." (P1)

The level of understanding was described as influencing the motivation by mothers to take their children for measles immunisation. One of the mothers whose child was vaccinated expressed herself as follows:

"As a mother you must take your child to the health facility to get vaccination ... it is okay for immunity ... to prevent diseases." ( $\mathrm{P} 3)$

\subsubsection{Other Factors Affecting Mothers' Decisions}

\section{Education Level}

The ability to read information on the child's health Passport was limited to information about the follow-up date. They all reported that they only concentrated on the follow-up appointment date and less attention was given to the type of vaccine or ideal age for administration of vaccines.

"I cannot read or write ... I (pauses) ... because I did not go to school ... I just know that we were informed at the clinic to take our children for follow-up and I asked the people I am staying with who can read ... to check the due date on the child's 'health passport'." (P2 - no schooling)

Most mothers revealed from their responses that they were not aware of the ideal age for measles immunisation, irrespective of their education level.

“... the age for measles immunisation is from baby to 10 years (laughs) ... or 10 months ... I am not sure ... we just check the date [follow-up date] on the child's Health Passport." (PC - Grade 11)

\section{Forgetfulness}

However, among the mothers whose children were immunised, there was the belief that it was important to be prepared to handle such competing priorities and deal effectively with the problem of forgetfulness.

“... You need your special bag for emergency travelling ... whereby you will have your particulars like personal documents and your clinic records ... it helps me. If I am to travel even if it is unplanned, I will have them ... that is where I took my child's Passport that I gave you." (P1)

Some mothers expressed concern about the lack of community meetings with the leaders to inform their members about the need for parents to take their children for immunisation. They also suggested that radio announcements as a means to remind and encourage mothers would be useful.

“... Community meetings should be held to get information from the leaders ... radio announcements to remind us ... we need information." (PD)

\section{Commitment}

Yet even those who believed that it was their responsibility to ensure that their children were immunised found it 
difficult to ensure this because of the competing activities that they had to attend to, as demonstrated by the following response:

"My child did not get measles immunisation because I went to help my parents at the farm ... it is very far from the heath facility and I stayed there for two months ... outreach services should be provided at such places, but for two months they [health workers] did not visit the place." (PC)

Laziness

Laziness was also seen as evidence of a lack of commitment by mothers whose children were not vaccinated, by those whose children were. They believed that these mothers were informed about the benefits of immunisation, yet they did not act on it.

"Some mothers do not take back their children to the clinic for immunisation ... due to laziness ... they don't care about why it is important for their children to receive immunisation." (P3)

Alcoholism

Alcohol was viewed as one of the barriers that contributed to low uptake of immunisation at their health facility, especially where there was no outreach point for immunisation services.

“... some parents just want to sit there at drinking places ... they sit at alcohol drinking places ... it is better ... maybe if there were many cars ... for the health workers to go out and provide immunisation at such places ... and outreach services have not been provided for a period of two months that I stayed at the farm ... and they are no other facilities for us to access immunisation services." (PC) "Alcoholism is a problem ... some parents just want to sit there at drinking places." (PA)

\subsection{Socio-Cultural Factors}

\subsubsection{Beliefs}

There was overwhelming acceptance of the importance of vaccination, as demonstrated by the responses from both the mothers whose children have and have not received measles immunisation. All participants, seven Catholics, two Apostolic and one Holy Trinity said that their religion did not prohibit immunisation. Therefore, religion was not a challenge for them.

“... No ... our religion does not stop us from using immunisation or any other medicines from the clinic or hospital ... mothers who don't take back their children at the clinic are just lazy." (P3)

There was an overwhelming response from mothers indicating that they did not believe in using traditional remedies. Once again laziness was used as an explanation for not taking their children.

"No ... we do not believe in traditional remedies ... the uptake of immunisation is low due to laziness of some mothers who fail to take back their children for immunisation ... alcohol abuse by some mothers also leads to less concern for the health of their children." (PA)

\subsubsection{Support Structures}

The support from the family can contribute to the commitment to take the child for immunisation. According to one of the mothers, the support from other family members was relied on to help her to take the child for follow-up measles immunisation.

"... I asked the people I am staying with who can read ... to check the due date on the child's 'Health Passport.", (P2)

The majority of mothers, by contrast, reported that the support from such structures was inadequate or missing.

"I am not employed ... I struggle all by myself to take care of my two children." (PE)

"The leaders are expected to work together with us, the community ... to take up our challenges ... it is not happening." (PB)

\subsection{Socio-Economic Factors}

According to some mothers, socio-economic status can influence their willingness to take the child for immunisation. Poverty arising from unemployment and lack of adequate resources from subsistence farming was described as a challenge for some mothers. This applied to both single and married mothers.

"I am married but we are poor ... we are not working (pauses) ... we are struggling to survive on subsistence farming ... but it is not easy to cope, we don't have money." (PB) 
“... I struggle by all means to get money to access health care services ...” (P1)

\subsection{Health System Factors for All Participants}

The majority of mothers had similar perceptions about the health facilities, as illustrated in the following comments. This applied to both sets of respondents.

\subsubsection{Availability of Services}

The majority of mothers raised complaints about availability of services at the clinic. Either the clinic was closed or services were not readily available. This included not being attended to when they took their children for follow-up measles immunisation, or being sent away on more than one occasion, which discouraged them from going back.

"... if you take back your child for immunisation ... you are told to go back but you are not given the reason for being sent back." (P1)

"I went to the clinic many times ... maybe four times over a month I have been sent back ... I got fed up ..."(PD)

The availability of outreach points in the community was suggested as something that would be very helpful for the areas and farms that are far away from the clinic, but the majority of mothers expressed concern that the services had not been readily offered for some time.

“... Outreach services should be provided at such places, but for two months they did not [health workers] visit the place." (PC)

\subsubsection{Staff Shortages}

The shortage of staff was reported by some mothers to have contributed to the delay in patients and mothers being attended to, resulting in long waiting times to receive services, including immunisation services.

"It was not good to be sent back repeatedly when you bring your child for immunisation ... maybe because we only had one nurse at a clinic ... I think that it is good that they (Ministry of Health) have allocated another nurse to this facility ... it is much better now ... we thank the ministry for additional staff." (PB)

\subsubsection{Attitudes of Staff}

Some mothers reported nurses' attitudes as unfriendly and characterised by a lack of empathy and sympathy, and by rudeness. This perceived unwelcoming approach of some nurses was reported to scare some mothers from approaching them.

"I was scared to ask because the nurse's attitude is unfriendly ... just a look at the face [nurse A's face] scares you off." (P1)

\subsection{Trustworthiness}

Trustworthiness of this study was ensured by using the criteria of Lincoln and Guba namely: credibility, transferability, dependability, and conformability of the study (Guba \& Lincon, 1985).

\section{Discussion}

The aim of this study was, to investigate the perceptions of mothers/caregivers on the factors that impact on the uptake of measles immunisation in the Nyangana Health District, with a view to improving measles immunisation coverage. The themes that emerged were: Individual factors, Social- cultural factors, Socio - economic factors and Health System factors. The findings are discussed in the next sections.

\subsection{Knowledge and Information About the Benefits of Immunisation}

The extent of knowledge and understanding of the measles disease and the consequences of missing the vaccination has an influence on the decisions that the mothers take about immunisation. This study also found that the mothers that had the information, and therefore took their children for vaccination, demonstrated determination despite the various reported challenges of accessing the services. Information was also thought to play a decisive role in determining health bahavior of individuals, it was observed that inadequate access to media among mothers increased the likelihood of incomplete immunization of children. Therefore, the dedication of few days a year to raise awareness through immunization campaigns by means of print electronic media and town cries were considered to be vital (Mohammed, 2016).

\subsection{Age of the Mother}

The study conducted in Ethiopia, indicated that the mother age had no influence on the children immunisation status (Mohammed, 2016) these findings are similar to the current study as it was observed that all 
mothers whose children had received measles immunisation were aged between 25 and 32 years, and the mothers whose children did not receive measles immunisation were aged between 24 and 37 years, the age diversity had no effect.

\subsection{Socio-Cultural Beliefs}

The mothers in this study reported that although immunisation was permitted in their culture, some mothers who had not taken their children for follow-up immunisation might have been influenced by their beliefs in traditional remedies. Religious beliefs in this study did not influence the acceptance of vaccination among mothers. This is in line with a study conducted in Saudi Arabia in which it was found that parents strongly agreed that child immunisation was not prohibited by their religion (Yousif, Albarraq, Abdallah \& Elbur, 2013).

\subsection{Socio-Economic Factors}

It was noted in this study that there was a diversity of financial support among married mothers who stayed at a distance from the health facility. Most mothers who took their children to be immunised indicated that they were supported financially with transport costs by their spouses, while those who did not, in particular single mothers, expressed concern at having to struggle all by themselves. These findings are supported by a study conducted in Dili, Timor-Leste in Asia, which indicated that mothers of children who were fully immunised received financial and moral support from their husbands (Amin, Real de Oliveira, Da Cunha, Brown, Favin \& Cappelier, 2013).

\subsection{The Influence of the Attitudes of Health Care Providers}

It became apparent from this study that the attitude of health care providers had an influence on the mothers' decisions to immunise their children. The value of good health professional advice is also described by Hill (2013), who demonstrated that health professionals are seen as a trustworthy source of information, and that parents are reported to actively seek their advice to inform their decision about whether to immunise their children or not.

\subsection{Access to Services}

Some mothers raised concerns about the inaccessibility of immunisation services, such as inconvenient schedules and time constraints. The current study findings are in line with some reasons that were given by mothers at Nyala locality in South Darfur State, Sudan (Ismail et.al, 2014), which included inconvenient times for immunisation, the vaccinator being absent and the unavailability of vaccines. Factors such as long waiting times, in a study conducted in in Nigeria (Oku et al., 2017) the absence of personnel at the health facility, in rural Nigeria (Jegede \& Owumi, 2013), have been noted, which reflect similar trends to this study's findings.

\subsection{Staff Shortages}

This study found that all mothers were concerned with the staff shortages and the absence of staff at the clinic, with some mothers claiming that it contributed to the low uptake. Some mothers dealt with this by seeking alternative immunisation services at other facilities, although this meant that they had to pay higher transport costs. In a study by Koskei et al. (2014) in Kachelichaba Division, Pokot County, Kenya, the absence of health personnel at the health facilities was also highlighted by the respondents among the reasons that contributed to failure to immunise children.

\section{Conclusions}

It was evident from the findings of this research that mothers perceive a number of interrelated factors between demand and supply side, as affecting the low uptake of measles immunisation. The demand side included: lack of information by some individual mothers on the importance of measles immunisation, lack of money for transport due to poverty, and lack of support structures while the supply side- the health system related factors included staff shortages, negative attitudes of clinic staff, lack of information sharing between health care providers and mothers, inconvenient timing of immunisation services at the clinic, long waiting times, inadequate out-reach services and lack of harmonization of record keeping between health care providers, long queues and the turning away of mothers without attending to them.

\subsection{Recommendations}

Based on the study findings, the following recommendations are made:

Strengthen social mobilization through campaigns, community gatherings, health educations sessions, radio announcements and the use of posters and flyers for information dissemination, both at individual and community levels, to address the value of immunisation services. The Ministry of Health and Social Services should review and improve the appointment of adequate staff that would be able to cater for immunisation services at the Clinic and for outreach services. The nurses should be trained in customer care services through free to grow workshops 
(life skills) in order to address the negative attitudes. Ministry of Poverty Eradication to sponsor community income generating projects that will help the community to have funds to access immunisation services from self-employment.

\subsection{Study Delimitations and Limitation}

The study was delimited to the mothers of children under the age of 5 who accessed services at Karukuta Clinic. The study results were limited to the study setting, and therefore the results derived from this study cannot be generalised to all mothers/caregivers of other children outside the study setting. In addition, the different dialects of language used by participants during the interviews could be regarded as a potential limitation.

\section{Acknowledgements}

We thank all the respondents who took time to participate in this study; without their participation this study would not have been possible. We also thank the Ministry of Health and Social Services for having granted us permission to conduct research in its health facilities.

\section{Competing Interests Statement}

The authors declare that there are no competing or potential conflicts of interest.

\section{References}

Amin, R., de Oliveira, T. J. C. R., Da Cunha, M., Brown, T. W., Favin, M., \& Cappelier, K. (2013). Factors Limiting Immunization Coverage in Urban Dili, Timor-Leste. Global Health Science Practices, 1(3), 417-427. http://dx. doi.org/10.9745/GHSP-D-13-00115

Brink, H, Van der Walt, C.,\& Van Rensburg, G. (2013). Fundamentals of Research Methodology for healthcare Professionals (3rd ed.). Cape Town, RSA: Juta and Company Ltd.

Dabbagh, A., Minal, K. P., Dumulard, L., Marta, G., Mulders, N. M., Okwa-Bele, J. M., ... James, L. G. (2017). Progress Towards Regional Measles Elimianation - worldwide, 2000-2016. Retrieved from https:www.ncbi.nlm.nih.gov/pmc/articles/PMC5689104/

Cockroft, A., Usman, M. U., Nyamucherera, O. F., Emori, H., Duke, B., Umar, N. A., \& Anderson, N. (2014). Why Children are not Vaccinated Against Measles: A Cross-Sectional Study in Two Nigerian States. Archives of Public Health, 72, 48. https://doi.org/10.1186/2049-3258-72-48

Greenwood B. (2014). The contribution of vaccination to global health: past.present and future. Phil.Trans. R. Soc. B, 369, 20130433. http://dx.doi.org/10.1098/rstb.2013.0433

Hill, M. C. (2013). Influencing Factors in MMR Immunization Decision Making: 582-592. Retrieved from eujournal.org/index.php/esj/article/download/1496/1505.

Ismail, I. T. A., El-Tayeb, E. M., Omer, M. D. F. A., Eltahir, Y. M., El-Sayed, E. A., \& Deribe, K. (2014). Assessment of Routine Immunization Coverage in Nyala Locality, Reasons Behind Incomplete Immunization in South Darfur State, Sudan. Asian Journal of Medicinal Sciences, 6(1), 1-8.

Jegede, A. S., \& Owumi, B. E. (2013). Factors Influencing Infant Immunisation Uptake in the Yoruba Community of Southwestern Nigeria. Journal of Community Medical Health Education, 3, 215. https://doi.org/10.4172/2161-0711.1000215>.

Koskei, A., Tabu, S., Malalu, P. K., Marete, I., Too, R., Peter, K. K., \& Tenge, C. (2014). Utilization of Essential Immunization Services among Children under Five Years in Kacheliba Division, Pokot County, Kenya. Science Journal of Public Health, 2(6), 617-623. Retrieved from http://dx.doi:10.11648/j.sjph.20140206.29

Maree, K. (2016). First steps in research. Pretoria: Van Schaik.

MoHSS (Ministry of Health and Social Services) \& ICF Macro 2010. Namibia Health Facility Census.2009: Key findings on Family Planning, Maternal and Child Health, and Malaria. MoHSS and ICF Macro, Windhoek, Namibia.

Masresha, B. G., Dixon, M. G., Kriss, J. L., Katsande, R., Shibeshi, M. E., Richard, L., ... Mihigo, R.(2017). Progress Toward Measles Elimination-African Region, 2013-2016. Retrieved from https://www.cdc.gov/mmwr/volumes/66/wr/mm6617a2.htm

Ministry of Health and Social Services (MoHSS). (2013). Namibia Demographic and Health Survey. Ministry of Health and Social Services, Windhoek.

Ministry of Health and Social Services (MoHSS). (2014). 541 - June Measles Updates. Ministry of Health and 
Social Services, Windhoek.

Mohammed, R. T. (2016). Assessment of Factors Associated with Incomplete Immunization among children Aged 12-23 months in Ethiopia. Masters Mini-Thesis. School of Public Health, University of the Western Cape. Retrieved from etd.uwc.ac.za/xmlui/handle/11394/4989

Oku A, Oyo-Ita A, Glenton C, Fretheim A, Ames H, Muloliwa A, et al. (2017) Perceptions and experiences of childhood vaccination. Communication stratergies among caregivers and health workers in Nigeria: A qualitative study. PloS ONE, 12(11), e0186733. https://doi.org/10.1371/journal.pone.0186733

UNICEF. (2014). Annual Report Namibia. Retrieved from https://www.unicef.org/about

World Health Organization [WHO]. (2017). Immunization and polio update immunization vaccine development. Retrieved from https://www.afro.who.int/sites/.../afr_-immunization-updates-march_apr_2017

WCDoH (). (2005). Facts About Immunisation: Epi Fact Sheet 1. Department of Health of South Africa of the Western Cape. Retrieved from https://www.westerncape.gov.za/text/2005/.../facts_about_immunisation...

Yousif, M. A., Albarraq, A. A., Abdallah, M. A. A., \& Elbur, A. I. (2013). Parents' Knowledge and Attitudes on Childhood Immunization, Taif, Saudi Arabia. Journal of Vaccines and Vaccination, 5, 215. https://doi.org/10.4172/2157-7560.1000215

\section{Copyrights}

Copyright for this article is retained by the author(s), with first publication rights granted to the journal.

This is an open-access article distributed under the terms and conditions of the Creative Commons Attribution license (http://creativecommons.org/licenses/by/4.0/). 